\title{
Association between ACE D allele and elite short distance swimming
}

\author{
Aldo Matos Costa • António José Silva • \\ Nuno Domingos Garrido • Hugo Louro • \\ Ricardo Jacó de Oliveira $\cdot$ Luiza Breitenfeld
}

Accepted: 29 April 2009 / Published online: 21 May 2009

(C) Springer-Verlag 2009

\begin{abstract}
The influence of ACE gene on athletic performance has been widely explored, and most of the published data refers to an I/D polymorphism leading to the presence (I allele) or absence (D allele) of a 287-bp sequence in intron 16, determining ACE activity in serum and tissues. A higher I allele frequency has been reported among elite endurance athletes, while the D allele was more frequent among those engaged in more power-orientated sports. However, on competitive swimming, the reproducibility of such associations is controversial. We thus compared the
\end{abstract}

A. M. Costa ( $\square)$

Department of Sports Science, University of Beira Interior, Rua Marquês d'Ávila e Bolama, 6201-001 Covilhã, Portugal e-mail: amcosta@ubi.pt

A. M. Costa - A. J. Silva - N. D. Garrido - H. Louro Research Centre in Sports, Health and Human Development, Vila Real, Portugal

A. J. Silva · N. D. Garrido

Department of Sports, Exercise and Health Sciences,

University of Trás-os-Montes and Alto Douro,

Vila Real, Portugal

H. Louro

Sports Science Institute of Rio Maior, Rio Maior, Portugal

R. J. de Oliveira

Catholic University of Brasilia, Brasilia, Brazil

L. Breitenfeld

Faculty of Health Sciences, University of Beira Interior, Covilhã, Portugal

A. M. Costa $\cdot$ L. Breitenfeld

CICS, Health Sciences Research Centre, Covilhã, Portugal
ACE genotype of elite swimmers with that of non-elite swimming cohort and of healthy control subjects. We thus sought an association of the ACE genotype of elite swimmers with their competitive distance. 39 Portuguese Olympic swimming candidates were classified as: $\operatorname{short~}(<200 \mathrm{~m})$ and middle $(400-1,500 \mathrm{~m})$ distance swimmers, respectively. A group of 32 non-elite swimmers were studied and classified as well, and a control group $(n=100)$ was selected from the Portuguese population. Chelex 100 was used for DNA extraction and genotype was determined by PCR-RFLP methods. We found that ACE genotype distribution and allelic frequency differs significantly by event distance only among elite swimmers $(P \leq 0.05)$. Moreover, the allelic frequency of the elite short distance swimmers differed significantly from that of the controls $(P=0.021)$. No associations were found between middle distance swimmers and controls. Our results seem to support an association between the $\mathrm{D}$ allele and elite short distance swimming.

Keywords Genetic polymorphisms - Angiotensin converting enzyme $\cdot$ Sports performance $\cdot$ Swimming

\section{Introduction}

The angiotensin converting enzyme (ACE) catalyzes the conversion of angiotensin I into angiotensin II (Ang II), a peptide that is physiologically active. Most of the Ang II effects are mediated predominantly through two specific human receptors (AT1 and AT2). Stimulation through the AT1 receptor by Ang II mediates an arterial vasoconstriction response. ACE also degrades bradykinin, whose action on the type 2 receptor (BK2) results in vasodilatation. Moreover, ACE has a role on the endocrine rennin-angiotensin 
system (RAS), controlling electrolyte balance and systemic blood pressure (Rieder et al. 1999). In addition, a local tissue RAS are well described in several tissues of the body, particularly in human myocardium (Dzau 1988), adipose tissue (Jonsson et al. 1994) and skeletal muscle (Dragovic et al. 1996; Reneland and Lithel 1994).

A polymorphism of the ACE gene has been described (Rigat et al. 1990) in which the presence (insertion, I allele) or absence (deletion, D allele) of a 287-base-pair DNA sequence within intron 16, resulting in three possible genotypes: II, DD and ID. Compared to the I allele, the presence of the $\mathrm{D}$ allele has been linked to an increased circulating (Cambien et al. 1994; Rigat et al. 1990) as well as tissue ACE activity (Costerousse et al. 1993; Danser et al. 1995). The D allele has been also associated with a higher risk for myocardial infarction and heart failure (Ledru et al. 1998) and with exerciseinduced left ventricular hypertrophy (Fatini et al. 2000; Hernandez et al. 2003; Montgomery et al. 1997; Kasikcioglu et al. 2004).

Studies concerning the effect of ACE genotype on skeletal muscle strength and mass in response to strength training have yielded inconsistent results (Folland et al. 2000; Pescatello et al. 2006; Thomis et al. 2004; Williams et al. 2005). Nevertheless, the ACE D allele seems to be overrepresented among elite athletes, who compete in poweroriented events (Myerson et al. 1999; Nazarov et al. 2001), and the I allele among elite endurance athletes (Alvarez et al. 2000; Collins et al. 2004; Gayagay et al. 1998; Moran et al. 2004). In fact, the II genotype has been associated with an altered submaximal hemodynamic responses with training (Hagberg et al. 2002) as well as with differences in $V \mathrm{O}_{2 \max }$ (Hagberg et al. 1998), although the results are controversial (Day et al. 2007; Rankinen et al. 2000a; Woods et al. 2002). Improved muscle efficiency is more likely to explain such differences (Williams et al. 2000). In what refers physical performance the results obtained by different research groups are also controversial (Lucia et al. 2005; Rankinen et al. 2000b; Scott et al. 2005; Taylor et al. 1999).

With respect to competitive swimming, to the best of our knowledge only three large studies (Nazarov et al. 2001; Woods et al. 2001; Tsianos et al. 2004) have directly characterized a possible link between ACE I/D polymorphism and performance in elite swimmers. However, regarding the swim event expertise, these studies had inconsistency between their sample stratification, which does not allow the comparative analysis of the results.

In this context, our main goal was to determine I/D allele frequencies of the Portuguese elite swimmers and to establish a more accurate association between I/D allele frequency with event specialization and swim level.

\section{Methods}

Subjects

After informed consent, elite $(n=39,22$ males and 17 females, $18.84 \pm 2.97$ years) and average ( $n=32,16$ males and 16 females, $18.07 \pm 3.03$ years) swimmers were recruited from the 2008 Swimming Portuguese Championship (long course pool). The swimmers were stratified into two homogeneous groups, based on their current distance event of expertise: short distance swimmers (SDS), between 50 and $200 \mathrm{~m}$ (mainly anaerobic events) and middle distance swimmers (MDS), 400-1,500 m (mixed anaerobic and aerobic events). A control group of healthy individuals ( $n=100,49$ males and 51 females, $21.83 \pm 2.92$ years) was also selected from the Portuguese population (college students) with no background in swimming.

The research study was approved by the local health services research ethics committee and was carried out according to the declaration of Helsinki.

\section{Genetic analysis}

Blood spots were collected onto filter paper (Albet, DP 400200), dried at room temperature and stored in separate plastic bags at $4^{\circ} \mathrm{C}$ until DNA extraction by Chelex protocol (Walsh et al. 1991). The ACE I/D polymorphism was genotyped using conditions previously described (Tiret et al. 1992). The PCR products were visualized by electrophoresis on $2 \%$ agarose gel and identified by ethidium bromide staining. ACE I/D alleles were visualized as a 490-bp band (I allele); a 190-bp band (D allele). II, DD and ID genotypes were identified.

\section{Statistical analysis}

Statistical analysis was performed using SigmaStat ${ }^{\circledR}$ Software Version 5.0 for Windows ${ }^{\circledR}$. Allele frequencies were estimated by gene-counting method. Genotype distribution and allele frequencies between groups were compared by Chi-Square test, as were estimates Hardy-Weinberg equilibrium. The Fisher's exact test was also used when appropriate. Statistical significance was defined as $P<0.05$.

\section{Results}

Data obtained for both genotype and allele distributions analysis is showed in Table 1. Genotypic frequencies in both swimmers and controls were in Hardy-Weinberg equilibrium, making selection bias less likely.

When we analyze the results obtained for the genotype distributions and allelic frequencies of the control group 
Table 1 ACE genotype distribution and allele frequencies of the swimmers and controls

\begin{tabular}{|c|c|c|c|c|c|c|}
\hline \multirow[t]{2}{*}{ Subjects } & \multirow[t]{2}{*}{$N$} & \multicolumn{3}{|c|}{ ACE genotype } & \multicolumn{2}{|c|}{ Allele frequency } \\
\hline & & DD & ID & II & $\mathrm{D}$ & I \\
\hline \multicolumn{7}{|c|}{ Swimmers overall } \\
\hline Elite & 39 & $20(0.51)$ & $14(0.36)$ & $5(0.13)$ & 0.69 & 0.31 \\
\hline Average & 32 & $14(0.44)$ & $13(0.40)$ & $5(0.16)$ & 0.64 & 0.36 \\
\hline \multicolumn{7}{|l|}{ SDS $(<200 \mathrm{~m})$} \\
\hline Elite & 25 & $14(0.56)$ & $11(0.44)$ & $0(0.0)$ & 0.78 & 0.22 \\
\hline Average & 23 & $9(0.39)$ & $10(0.44)$ & $4(0.17)$ & 0.61 & 0.39 \\
\hline \multicolumn{7}{|c|}{ MDS (400-1,500 m) } \\
\hline Elite & 14 & $6(0.43)$ & $3(0.21)$ & $5(0.36)$ & 0.54 & 0.46 \\
\hline Average & 9 & $5(0.56)$ & $3(0.33)$ & $1(0.11)$ & 0.72 & 0.28 \\
\hline Control group & 100 & $39(0.39)$ & $45(0.45)$ & $16(0.16)$ & 0.62 & 0.38 \\
\hline
\end{tabular}

and the swimmers overall (elite and average), there are no statistical differences between them $(P>0.05)$. However, when the swimmers are stratified into two homogeneous groups, based on their current distance event of expertise (SDS and MDS), we were able to verify that the allelic frequencies of elite SDS are significant different toward control group $(P=0.021)$. In addition, there is a higher frequency of the DD genotype in elite SDS when compared with controls $(P=0.029)$. In contrast, when average swimmers were considered (SDS and MDS groups), the results show no significant statistical differences $(P>0.05)$ in relation to controls.

As seen in Fig. 1, the analysis by race distance shows that the allelic frequencies of elite SDS are different when compared to the elite MDS $(P<0.001)$. This was due to an excess frequency of the DD genotype and a decrease frequency of II genotype in elite SDS, when compared with elite MDS group. These differences are statistically significant $(P=0.009)$. The same procedure was performed on

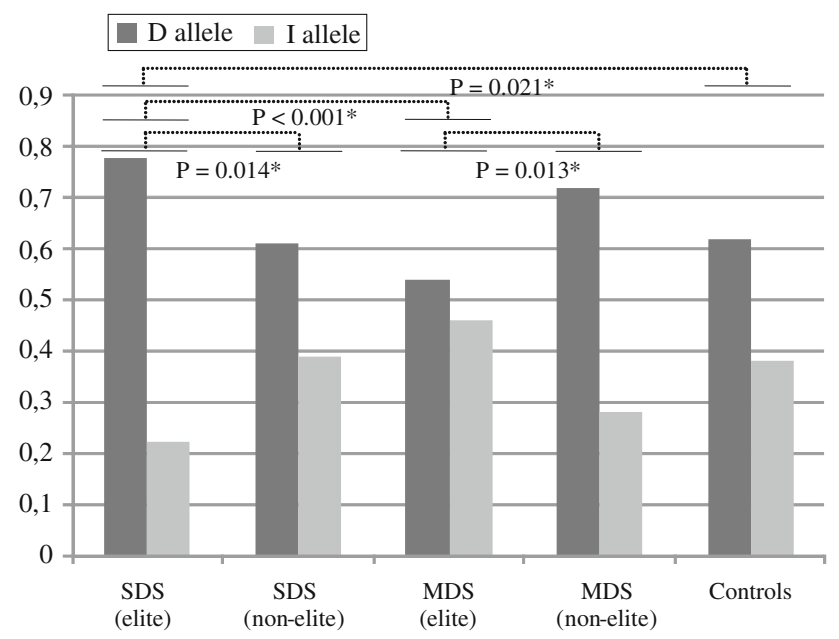

Fig. 1 Allelic frequencies of stratified (SDS and MDS) elite and average swimmers groups and controls average swimmers, and no significant statistical differences $(P>0.05)$ were found. Furthermore, allelic frequencies of stratified elite and average swimmers groups are significantly different: between elite SDS and average SDS $(P=0.014)$; between elite MDS and average MDS $(P=0.013)$.

\section{Discussion}

Several studies revealed the general tendency of individuals with I allele to show superior performance in endurance sports such as rowers (Gayagay et al. 1998), long-distance runners (Moran et al. 2004; Myerson et al. 1999), triathletes (Collins et al. 2004) and cyclists (Alvarez et al. 2000).

Among competitive swimmers, Woods et al. (2001) reported an excess frequency of the D allele overall, with no significant variation in I allele frequency by event distance ( $>400 \mathrm{~m}$ and $<400 \mathrm{~m}$ ). Nazarov et al. (2001) stratified swimmers in three event groups with different durations ( $<1 \mathrm{~min}, 1-20 \mathrm{~min}$ and longer than $20 \mathrm{~min}$ ), not by regular trial distance, and found an excess of the $\mathrm{D}$ allele in short distance swimmers $(P=0.042)$ and of the I allele in middle distance swimmers $(P=0.042)$. Tsianos et al. (2004) compared long open water swimmers competing over distances of 5,10 , and $25 \mathrm{~km}$, and found an association of the ACE I allele with elite endurance athletic performance, and the $\mathrm{D}$ allele with shorter-distance swimming.

Our results support these previous observations, demonstrating an association of the $\mathrm{D}$ allele with elite short-distance swimmer status $(P=0.021)$. However, the power of the performed test $(0.638 ; \alpha=0.05)$ was below the desired power of 0.80 . Therefore, we should interpret these findings cautiously.

These differences are sustained mainly by an excess of DD genotype frequency and a low II genotype on the elite SDS group compared with elite MDS or to control group. The fact that this study applied more rigorous limits to establish the SDS group stratification (50-200 m) highlight 
the relation of the ACE D allele with a better performance in shorter and truly anaerobic swimming events (200 m and less). As seen in Fig. 1, the allelic frequencies of elite SDS are different, when compared to elite MDS $(P<0.001)$. The power of the performed test $(\alpha=0.05)$ was 0.947 , above the desired power of 0.80 . In fact, some studies have associated the $\mathrm{D}$ allele with greater increased in left ventricular mass (Fatini et al. 2000; Hernandez et al. 2003; Montgomery et al. 1997; Kasikcioglu et al. 2004), higher $V O_{2 \max }$ (Hagberg et al. 1998) and with differences in skeletal muscle strength gain (Folland et al. 2000; Williams et al. 2005). Moreover, Zhang et al. (2003) showed linear trends for decreases in type I fibers and increases in type IIb fibers from ACE II to ID and to DD genotypes. We considered that these are all possible mechanism for the association between the ACE genotype and power-oriented athletic performance. These effects may be explained, as mentioned before, by the association of the $\mathrm{D}$ allele with increased angiotensin II, a growth factor (Liu et al. 1998), and reduced bradykinin (Murphey et al. 2000), a growth inhibitor (Linz and Scholkens 1992).

The I allele frequency value for the MDS elite group is higher than the value obtained for the SDS elite group; these results are consistent with Myerson et al. (1999) results that found an increasing frequency of the I allele with running distance $(0.35,0.53$ and 0.62 for the 200 , $400-3,000$ and $5,000 \mathrm{~m}$, respectively; $P=0.009$ ). Tsianos et al. (2004) also confirmed this hypothesis among elite open water swimmers competing at $1-10 \mathrm{~km}$ distances and those best at $25 \mathrm{~km}$ races $(P=0.07)$. Nevertheless, in our study, the differences observed are not significant when compared with controls $(P=0.316)$. As Cerit et al. (2006) suggests that the threshold of effectiveness for the significant influence of I allele on endurance is located somewhere between 10 and $30 \mathrm{~min}$. However, with regard to swimming, this will only be recognized over far greater distances, as suggested also by other authors (Tsianos et al. 2004). These facts could explain our results as the best performance times of the athletes included on elite MDS group are between 4 and $16 \mathrm{~min}$, for the 400 and 1,500 m events, respectively. However, the power of the performed test $(0.158, \alpha=0.05)$ was below the desired power of 0.80 . Despite the sample being representative of elite swimmers in Portugal, its data extrapolation, especially regarding the longer distance swimmers (as with any such small samples) should be treated with caution when viewed alone.

Additionally, by a priori hypothesis we had previously identified no significant differences in allelic frequencies between 400 and $1,500 \mathrm{~m}$ specialists $(P>0.05$, data not shown). This result lead us to agree with Woods et al. (2001) about the fact the relationship between D allele and short time/distances tasks is distinct from that found between I allele and enhanced endurance performance. The difference between these relationships is likely to be related to improved substrate delivery (Woods et al. 2000) and muscle efficiency (Williams et al. 2000) with consequent conservation of energy stores (Montgomery et al. 1999).

As seen in Fig. 1, allelic frequencies of stratified elite and average swimmers groups are significantly different (between elite SDS and average SDS, $P=0.014$; between elite MDS and average MDS, $P=0.013$ ). The power of the performed tests $(\alpha=0.05)$ was below the desired power of 0.80 (0.695 and 0.707 , respectively). Therefore, we should interpret these results cautiously. Even so, one expects that $D$ allele frequency would be highest in average SDS when compared to controls; this is not the case. Similarly, the I allele frequency remains almost unchanged between average MDS and controls. These results, consistent with Nazarov et al. (2001), highlight the need for such genetic studies to separate out elite from non-elite competitors, and also to study a single sporting discipline over distance.

Like in several others studies (Taylor et al. 1999; Woods et al. 2001; Nazarov et al. 2001) a gender separate analysis was not our main focus. The numbers and proportion of elite female swimmers were smaller than those for men (17 elite female swimmers vs. 22 elite male swimmers). Moreover, further event distance stratification within each gender will became insufficient for gender-specific analysis. Among the 22 elite male swimmers, 16 were SDS but only 6 were MDS; among the 17 elite female swimmers, 10 were SDS and 8 were MDS. In respect to the 16 average male swimmers included in this study, 10 were SDS and 6 were MDS. Along with the 16 average female swimmers, 13 were SDS but only 3 were MDS. Given known components of skeletal muscle tissue-based renin-angiotensin system are markedly affected by gender (Fischer et al. 2002), it would be quite accurate to proceed further investigations recognizing this separate analysis. Indeed, this is an important limitation of the present study that warrants consideration.

In conclusion, our results seem to support an association of the ACE D allele with elite short distance swimming status. Likewise, the D allele frequencies decrease significantly beyond the 200-m distance threshold. The elite middle distance swimmers were no different to controls for allele frequency, as other authors previously suggested. However, further studies with large samples of elite athletes will be performed to reinforce the confirmation of these findings.

Acknowledgments We thank Portuguese Swimming Federation for authorization and technical support. We are also grateful to the Portuguese Science and Technology Foundation (SFRH/BD/40243/2007) for financial support. All subjects sign an informed consent approved by local health sciences research ethics committee. The experiments comply with the current Portuguese laws and carried out according to the Helsinki Declaration. 
Conflict of interest statement All authors declare that they have no conflict of interest.

\section{References}

Alvarez R, Terrados N, Ortolano R, Iglesias-Cubero G, Reguero J, Batalla A, Cortina A, Fernández-García B, Rodríguez C, Braga S, Alvarez V, Coto E (2000) Genetic variation in the renin-angiotensin system and athletic performance. Eur J Appl Physiol 82:117120. doi: $10.1007 / \mathrm{s} 004210050660$

Cambien F, Costerousse O, Tiret L, Poirier O, Lecerf L, Gonzales M, Evans A, Arveiler D, Cambou J, Luc G (1994) Plasma level and gene polymorphism of angiotensinconverting enzyme in relation to myocardial infarction. Circulation 90:669-676

Cerit M, Colakoglu M, Erdogan M, Berdeli A, Cam F (2006) Relationship between ACE genotype and short duration aerobic performance development. Eur J Appl Physiol 98:461-465. doi:10. 1007/s00421-006-0286-6

Collins M, Xenophontos S, Carilou M, Mokone G, Hudson D, Anastasiades L, Noakes T (2004) The ACE gene and endurance performance during the South African Ironman triathlons. Med Sci Sports Exerc 36(8):1314-1320. doi:10.1249/01.MSS.0000 135779.41475.42

Costerousse O, Allegrini J, Lopez M, Alhenc-Gelas F (1993) Angiotensin I-converting enzyme in human circulating mononuclear cells: genetic polymorphism of expression in T-lymphocytes. Biochem J 290(Pt 1):33-40

Danser A, Schalekamp M, Bax W, Van-den-Brink A, Saxena P, Riegger G (1995) Angiotensin-converting enzyme in the human heart: effect of the deletion/insertion polymorphism. Circulation 92:1387-1388

Day S, Gohlke P, Dhamrait S, Williams A (2007) No correlation between circulating ACE activity and $\mathrm{VO} 2 \mathrm{max}$ or mechanical efficiency in women. Eur J Appl Physiol 99(1):11-18. doi:10.1007/ s00421-006-0309-3

Dragovic T, Minhall R, Jackman HL, Wang L-X, Erdos EG (1996) Kininase II-type enzymes: their putative role in muscle energy metabolism. Diabetes 45(Suppl 1):S34-S37

Dzau VJ (1988) Circulating vs local renin-angiotensin system in cardiovascular homeostasis. Circulation 77(Suppl 1):I4-I13

Fatini C, Guazzelli R, Manetti P, Battaglini B, Gensini F, Vono R, Toncelli L, Zilli P, Capalbo A, Abbate R, Gensini GF, Galanti G (2000) RAS genes influence exercise-induced left ventricular hypertrophy: an elite athletes study. Med Sci Sports Exerc 32(11):1868-1872. doi:10.1097/00005768-200011000-00008

Fischer M, Baessler A, Schunkert H (2002) Renin angiotensin system and gender differences in the cardiovascular system. Cardiovasc Res 53(3):672-677. doi:10.1016/S0008-6363(01)00479-5

Folland J, Leach B, Little T, Hawker K, Myerson S, Montgomery H, Jones D (2000) Angiotensin-converting enzyme genotype affects the response of human skeletal muscle to functional overload. Exp Physiol 85(5):575-579. doi:10.1017/S09580670000 20571

Gayagay G, Yu B, Hambly B, Boston T, Hahn A, Celermajer D, Trent R (1998) Elite endurance athletes and the ACE I allele: the role of genes in athletic performance. Hum Genet 103(1):48-50. doi: $10.1007 / \mathrm{s} 004390050781$

Hagberg JM, Ferrell RE, McCole SD, Wilund KR, Moore GE (1998) VO2max is associated with ACE genotype in postmenopausal women. J Appl Physiol 85(5):1842-1846

Hagberg JM, McCole SD, Brown MD, Ferrell RE, Wilund KR, Huberty A, Douglass LW, Moore GE (2002) ACE insertion/deletion polymorphism and submaximal exercise hemodynamics in post menopausal women. J Appl Physiol 92(3):1083-1088
Hernandez D, De la Rosa A, Barragan A, Barrios Y, Salido E, Torres A, Martín B, Laynez I, Duque A, De Vera A, Lorenzo V, González A (2003) The ACE/DD genotype is associated with the extent of exercise-induced left ventricular growth in endurance athletes. J Am Coll Cardiol 42:527-532. doi:10.1016/S07351097(03)00642-9

Jonsson JR, Game PA, Head RJ, Frewin DB (1994) The expression and localisation of the angiotensin-converting enzyme mRNA in human adipose tissue. Blood Press 3:72-75. doi:10.3109/ 08037059409101524

Kasikcioglu E, Kayserilioglu A, Ciloglu F, Akhan H, Oflaz H, Yildiz S, Peker I (2004) Angiotensin converting enzyme gene polymorphism, left ventricular remodeling, and exercise capacity in strength-trained athletes. Heart Vessels 19:287-293. doi:10.1007/ s00380-004-0783-7

Ledru F, Blanchard D, Battaglia S, Jeunemaitre X, Courbon D, Guize L, Germonprez J-L, Ducimetiere P, Diébold B (1998) Relation between severity of coronary artery disease, left ventricular function and myocardial infarction, and influence of the ACE I/D gene polymorphism. Am J Cardiol 82(2):160-165. doi:10.1016/ S0002-9149(98)00304-X

Linz W, Scholkens BA (1992) A specific B2-bradykinin receptor antagonist HOE 140 abolishes the antihypertrophic effect of ramipril. Br J Pharmacol 105:771-772

Liu Y, Leri A, Li B et al (1998) Angiotensin II stimulation in vitro induces hypertrophy of normal and postinfarcted ventricular myocytes. Circ Res 82:1145-1159

Lucia A, Gomez-Gallego F, Chicharro J, Hoyos J, Celaya K, Cordova A, Villa G, Alonso J, Barriopedro M, Perez M, Earnest C (2005) Is there no association between ACE and CKMM polymorphisms and cycling performance status during 3-weeks races? Int J Sports Med 26(6):442-447. doi:10.1055/s-2004-821108

Montgomery HE, Clarkson P, Dollery CM, Prasad K, Losi M-A, Hemingway H, Statters D, Jubb M, Girvain M, Varnava A, World M, Deanfield J, Talmud P, McEwan JR, McKenna WJ, Humphries S (1997) Association of angiotensin-converting enzyme gene I/D polymorphism with change in left ventricular mass in response to physical training. Circulation 96:741-747

Montgomery H, Clarkson P, Barnard M, Bell J, Brynes A, Dollery C, Hajnal J, Hemingway H, Mercer D, Jarman P, Marshall R, Prasad K, Rayson M, Saeed N, Talmud P, Thomas L, Jubb M, World M, Humphries S (1999) Angiotensin-converting-enzyme gene insertion/deletion polymorphism and response to physical training. Lancet 353(9152):541-545. doi:10.1016/S0140-6736 (98)07131-1

Moran C, Scott R, Wilson R, Georgiades E, Goodwin W, Wolde B, Pitsiladis Y (2004) Increased frequency of an ACE polymorphism in Ethiopian elite marathon runners. Med Sci Sports Exerc 36(5):S259. doi:10.1097/00005768-200405001-01240

Murphey LJ, Gainer JV, Vaughan DE, Brown NJ (2000) Angiotensinconverting enzyme insertion/deletion polymorphism modulates the human in vivo metabolism of bradykinin. Circulation 102:829-832

Myerson S, Hemingway H, Budget R, Martin J, Humphries S, Montgomery H (1999) Human angiotensin I-converting enzyme gene and endurance performance. J Appl Physiol 87(4):1313-1316

Nazarov I, Woods D, Montgomery H, Shneider O, Kazakov V, Tomilin N, Rogozkin V (2001) The angiotensin converting enzyme I/D polymorphism in Russian athletes. Eur J Hum Genet 9(10):797-801. doi:10.1038/sj.ejhg.5200711

Pescatello L, Kostek M, Gordish-dressman H, Thompson P, Seip R, Price T, Angelopoulos T, Clarkson P, Gordon P, Moyna N, Visich P, Zoeller R, Devaney J, Hoffman E (2006) ACE ID genotype and the muscle strength and size response to unilateral resistance training. Med Sci Sports Exerc 38(6):1074-1081. doi:10.1249/ 01 mss.0000222835.28273.80 
Rankinen T, Perusse L, Gagnon J, Chagnon Y, Leon A, Skinner J, Wilmore J, Rao D, Bouchard C (2000a) Angiotensin-converting enzyme ID polymorphism and fitness phenotype in the Heritage Family Study. J Appl Physiol 88(3):1029-1035

Rankinen T, Wolfarth B, Simoneau JA, Maier-Lenz D, Rauramaa R, Rivera MA, Boulay MR, Chagnon YC, Perusse L, Keul J, Bouchard C (2000b) No association between angiotensinconverting enzyme ID polymorphism and elite endurance athlete status. J Appl Physiol 88:1571-1575

Reneland R, Lithel H (1994) Angiotensin-converting enzyme in human skeletal muscle: a simple in vitro assay of activity in needle biopsy specimens. Scand J Clin Lab Invest 54:105-111. doi:10.3109/00365519409086516

Rieder M, Taylor S, Clark A, Nickerson D (1999) Sequence variation in the human angiotesin converting enzyme. Nat Genet 22:59-62. doi: $10.1038 / 8760$

Rigat B, Hubert C, Alhenc-Gelas F, Cambien F, Corvol P, Soubrier F (1990) An insertion/deletion polymorphism in the variance of serum enzyme levels. J Clin Invest 86(4):1343-1346. doi:10. 1172/JCI114844

Scott R, Moran C, Wilson R, Onywera V, Boit M, Goodwin W, Gohlke P, Payne J, Montgomery H, Pitsiladis Y (2005) No association between Angiotensin Converting Enzyme (ACE) gene variation and endurance athlete status in Kenyans. Comp Biochem Physiol A 141(2):169-175. doi:10.1016/j.cbpb.2005.05.001

Taylor R, Mamotte C, Fallon K, Bockxmeer F (1999) Elite athletes and the gene for angiotensin-converting enzyme. J Appl Physiol 87(3): 1035-1037

Thomis MA, Huygens W, Heuninckx S, Chagnon M, Maes HH, Claessens A, Vlietinck R, Bouchard C, Beunen GP (2004) Exploration of myostatin polymorphism and the angiotensin-converting enzyme insertion/deletion genotype in responses of human muscle to strength training. Eur J Appl Physiol 92:267-274. doi:10.1007/s00421-004-1093-6

Tiret L, Rigat B, Visvikis S, Breda C, Corvol P, Cambien F, Soubrier F (1992) Evidence, from combined segregation, and linkage analysis, that a variant of the angiotensin I-converting enzyme (ACE) gene controls plasma ACE levels. Am J Hum Genet 51(1):197-205

Tsianos G, Sanders J, Dhamrait S, Humphries S, Grant S, Montgomery $H$ (2004) The ACE gene polymorphism and elite endurance swimming. Eur J Appl Physiol 93(3):360-362

Walsh P, Metzger D, Higuchi R (1991) Chelex 100 as a medium for simple extraction of DNA for PCR-based typing from forensic material. Biotechniques 10(4):506-513

Williams AG, Rayson MP, Jubb M, Word M, Wood DR, Hayward M, Martin J, Humphriest SE (2000) The ACE gene and muscle performance. Nature 403:614. doi:10.1038/47534

Williams AG, Day SH, Folland JP, Gohlke P, Dhamrait S, Montgomery HE (2005) Circulating angiotensin converting enzyme activity is correlated with muscle strength. Med Sci Sports Exerc 37:944948

Woods DR, Humphries SE, Montgomery HE (2000) The ACE I/D Polymorphism and Human Physical Performance. Trends Endocrinol Metab 11:416-420. doi:10.1016/S1043-2760(00)00310-6

Woods D, Hickman M, Jamshidi Y, Brull D, Vassiliou V, Jones A, Humphries S, Montgomery H (2001) Elite swimmers and D allele of the ACE I/D polymorphism. Hum Genet 108(3):230-232. doi: $10.1007 / \mathrm{s} 004390100466$

Woods D, World M, Rayson M, Williams A, Jubb M, Jamshidi Y, Hayward M, Mary D, Humphries S, Montgomery H (2002) Endurance enhancement related to the human angiotensin I-converting enzyme I-D polymorphism is not due to differences in the cardio respiratory response to training. Eur J Appl Physiol 86:240-244. doi:10.1007/s00421-001-0545-5

Zhang B, Tanaka H, Shono N, Miura S, Kiyonaga A, Shindo M, Saku $\mathrm{K}$ (2003) The I allele of the angiotensin-converting enzyme gene is associated with an increased percentage of slow-twitch type I fibers in human skeletal muscle. Clin Genet 63(2):139-144. doi:10.1034/j.1399-0004.2003.00029.x 